\title{
EFFICACY OF ULTRASONOGRAPHY IN THYROID CANCER
}

Mumtaz Ahmad Ansari ${ }^{1}$

\section{HOW TO CITE THIS ARTICLE:}

Mumtaz Ahmad Ansari. "Efficacy of Ultrasonography in Thyroid Cancer". Journal of Evolution of Medical and Dental Sciences 2014; Vol. 3, Issue 08, February 24; Page: 1828-1831, DOI: 10.14260/jemds/2014/2064

ABSTRACT: OBJECTIVE: To evaluate the ultrasonographic (US) findings of medullary thyroid carcinoma as compared to findings of papillary thyroid carcinoma. MATERIALS AND METHODS: The study included 21 cases of MTC and 114 cases of PTCs that were diagnosed between 2005 and 2011. Two radiologists reached a consensus in the evaluation of the US findings. The sonographic findings of medullary and papillary carcinomas were compared with use of the chi-square test. RESULTS: The predominant sonographic features of MTCs were solid internal content (91\%), an ovoid to round shape (57\%), marked hypoechogenicity (52\%) and calcifications (52\%). Lesions in MTCs were larger than those in PTCs but this difference was not statistically significant. An ovoid to round shape was more prevalent in MTC lesions than PTC lesions and this was the only statistically significant difference $(p<0.05)$. CONCLUSION: Currently accepted sonographic criteria can be applied for a diagnosis of MTCs. The US findings for MTC are not greatly different from PTC except for the prevalence of an ovoid to round shape in the former.

KEYWORDS: Thyroid, thyroid ultrasonography, thyroid neoplasms.

INTRODUCTION: Malignant tumors of thyroid follicular cell origin have traditionally been classified as either well-differentiated thyroid carcinoma (WDTC), which is composed of papillary and follicular carcinoma, or undifferentiated/anaplastic thyroid carcinoma (ATC). The vast majority of patients with WDTC have an excellent prognosis regardless of the types of treatment used, whereas patients with ATC uniformly have a poor prognosis ${ }^{1}$. Thyroid sonography has been widely used to differentiate benign from malignant nodules and to guide fine-needle aspiration (FNA) cytology for nodules suspected of being malignant ${ }^{2}$. Sonographic features predictive of malignant nodules include the presence of microcalcifications, marked hypoechogenicity, microlobulated or irregular or spiculated margin, taller-than-wide shape, absence of a halo, predominantly solid composition, and intranodular vascularity ${ }^{2-6}$. Sonographic criteria for a thyroid malignancy have been established for a papillary thyroid carcinoma (PTC) in most studies ${ }^{2-6}$. It is not well known whether the application of the same criteria for MTC is acceptable. The purpose of this study was to evaluate whether sonography can be used to diagnose an MTC as a malignancy on the basis of widely accepted sonographic criteria and to determine which sonographic findings of MTC are different from those of PTC.

\section{MATERIALS AND METHODS:}

Patient selection: This retrospective study included 21 cases (18 patients; 15 females and 3 males; age range, 26-70 years; mean patient age, 55 years) that were surgically diagnosed as an MTC between 2008 and 2011. Three patients had bilateral MTCs (16.7\%). Sixteen patients had a sporadic MTC, and two patients had type IIa multiple endocrine neoplasia (MEN). As the MTC US findings of MTC were to be compared with the PTC US findings, a, control group of 114 PTC cases that were 
surgically diagnosed during 2007 (99 patients; 85 females and 14 males; age range, 27-76 years; mean age, 50.4 years) was established. Fifteen patients had bilateral PTCs (13.2\%).

Ultrasonography and Data analysis: Sonography was performed as a baseline study before surgery. Thyroid ultrasound was performed by radiologists using Toshiba Xerio 30 at 7-14 MHz. Retrospective review of the sonographic images was performed in consensus by two radiologists with experience in thyroid imaging who were blinded to the pathologic results. They determined the sonographic characteristics of nodules, including the presence of cystic change, shape (ovoid to round, taller-than-wide, or irregular), margin (circumscribed, spiculated, or ill-defined), echogenicity (markedly hypoechoic, hypoechoic, or isoechoic), echotexture of the solid portion (homogeneous or heterogeneous), presence of calcifications, and calcification type if present (microcalcifications, macrocalcifications, or rim calcifications). The size of nodules was recorded according to previous sonographic reports.

The sonographic findings of medullary and papillary carcinomas were compared with use of the chi square test. A p-value of less than 0.05 was defined as statistically significant.

RESULTS: A summary of the results is given in table 1.

\begin{tabular}{|c|c|c|c|}
\hline Ultrasonographic Findings & $\begin{array}{l}\text { Medulary Carcinoma } \\
\qquad(n=21)\end{array}$ & $\begin{array}{l}\text { Papillary Carcinoma } \\
\qquad(n=114)\end{array}$ & P value \\
\hline Lesion size & $19 \pm 13.9 \mathrm{~mm}$ & $11 \pm 7.5 \mathrm{~mm}$ & $<0.05$ \\
\hline \multicolumn{4}{|l|}{ Internal content } \\
\hline solid & $19(90.5 \%)$ & $110(96.5 \%)$ & 0.219 \\
\hline predominantly solid & $2(9.5 \%)$ & $4(3.5 \%)$ & \\
\hline predominantly cystic & $0(0 \%)$ & $0(0 \%)$ & \\
\hline cystic & $0(0 \%)$ & $0(0 \%)$ & \\
\hline \multicolumn{4}{|l|}{ Shape } \\
\hline ovoid to round & $12(57.1 \%)$ & $29(25.4 \%)$ & $<0.05$ \\
\hline "taller than wide & $4(19.0 \%)$ & $48(42.1 \%)$ & \\
\hline irregular & $5(23.8 \%)$ & $37(32.5 \%)$ & \\
\hline \multicolumn{4}{|l|}{ Margin } \\
\hline smooth & $4(19.0 \%)$ & $22(19.3 \%)$ & 0.964 \\
\hline "spiculated & $9(42.8 \%)$ & $44(38.6 \%)$ & \\
\hline ill-defined & $8(38.1 \%)$ & $48(42.1 \%)$ & \\
\hline \multicolumn{4}{|l|}{ Echogenicity } \\
\hline 'markedly hypoechoic & $11(52.4 \%)$ & $65(57.0 \%)$ & 0.894 \\
\hline hypoechoic & $9(42.9 \%)$ & $42(36.8 \%)$ & \\
\hline isoechoic & $1(4.8 \%)$ & $5(4.4 \%)$ & \\
\hline hyperechoic & $0(0 \%)$ & $2(1.8 \%)$ & \\
\hline \multicolumn{4}{|l|}{ Calcifications } \\
\hline no calcifications & $10(47.6 \%)$ & $37(32.5 \%)$ & 0.348 \\
\hline "microcalcifications & $6(28.6 \%)$ & $53(46.5 \%)$ & \\
\hline "macrocalcifications & $5(23.8 \%)$ & $21(18.4 \%)$ & \\
\hline rim calcifications & $0(0 \%)$ & $3(2.6 \%)$ & \\
\hline
\end{tabular}

For MTCs, a solid internal content (90.5\%), ovoid to round shape (57.1\%), marked hypoechogenicity (52.4\%), microcalcifications or macrocalcifications (52.4\%) and a spiculated or illdefined margin (80.9\%) were the prevailing findings seen on US. For 21 MTCs, 17(81\%) were 
categorized as suspicious malignant nodules, and four (19\%) were categorized as indeterminate nodules. None of the lesions were categorized as probably benign nodules. For the PTCs, the prevailing findings as seen on US were a solid internal content (96.5\%), taller than wide shape (48\%), irregular border (42.1\%), marked hypoechogenicity (57.0\%) and microcalcifications or macrocalcifications (64.9\%). For 114 PTCs, 107(94\%) were categorized as suspicious malignant nodules and seven (6\%) were categorized as indeterminate nodules.

DISCUSSION: Fine needle aspiration (FNA) of thyroid nodules has become one of the most useful, safe and accurate methods used to diagnose thyroid pathology. US findings are important to evaluate and prioritize nodules during FNA. Several studies have been designed to evaluate the sonographic criteria for malignant thyroid nodules that are subjected to an FNA.2-11 Most cases of carcinomas included in these studies were papillary or follicular thyroid carcinomas, and MTCs were included in less than 10 cases as malignant nodules. There has been little data reported on the sonographic appearance of MTCs. Gorman et al.12 reported that all six MTCs in their study appeared hypoechoic and relatively well defined, and bright echogenic foci were seen within the thyroid mass in five patients. In 2002, Saller et al. ${ }^{13}$ reported the US findings of 19 MTC cases. All of the cases showed hypoechogenicity. In our study, MTCs were significantly larger in a diameter compared with PTCs at the time of diagnosis.

However, nodule size was not predictive of malignancy because the likelihood of cancer in a thyroid nodule has been shown to be the same regardless of the size measured at sonography $2,3,14$. Studies comparing the US findings of MTC with PTC have not been previously conducted and we compared and analyzed the US findings of 21 MTC cases and 114 PTC cases. The mean size of MTC nodules was larger than that of PTC nodules $(19 \pm 13.9 \mathrm{~mm}$ vs. $11 \pm 7.5 \mathrm{~mm}, \mathrm{p}<0.05)$. In a comparison of the US findings, $57 \%$ of MTCs and $25 \%$ of PTCs exhibited an ovoid to round shape, which was significantly higher for the MTC nodules $(\mathrm{p}<0.05)$. However, internal content, margin, echogenicity and frequency of calcifications were not significantly different between MTCs and PTCs.

CONCLUSION: In conclusion, MTCs and PTCs may have overlapping sonographic features of malignancy and currently accepted sonographic criteria can be applied for a diagnosis of MTCs as malignancy. The US findings were not greatly different between MTCs and PTCs, except that the ovoid to round shape was more abundant in MTCs.

\section{REFERENCES:}

1. Shaha AR. Implications of prognostic factors and risk groups in the management of differentiated thyroid cancer. Laryngoscope. 2004; 114:393-402.

2. Frates MC, Benson CB, Charboneau JW, et al. Management of thyroid nodules detected at US: Society of Radiologists in Ultrasound consensus conference statement. Radiology 2005; 237:794-800.

3. Kim EK, Park CS, Chung WY, et al. New sonographic criteria for recommending fine-needle aspiration biopsy of nonpalpable solid nodules of the thyroid. AJR 2002; 178:687-691.

4. Hoang JK, Lee WK, Lee M, Johnson D, Farrell S. US features of thyroid malignancy: pearls and pitfalls. RadioGraphics 2007; 27:847-860; discussion, 861-865. 


\section{ORIGINAL ARTICLE}

5. Desser TS, Kamaya A. Ultrasound of thyroid nodules. Neuroimaging Clin N Am 2008; 18:463478 [vii].

6. Moon WJ, Jung SL, Lee JH, et al. Benign and malignant thyroid nodules: US differentiationmulticenter retrospective study. Radiology 2008; 247:762-770.

7. Brkljacic B, Cuk V, Tomic-Brzac H, Bence-Zigman Z, Delic-Brkljacic D, Drinkovic I. Ultrasonic evaluation of benign and malignant nodules in echographically multinodular thyroids. J Clin Ultrasound 1994; 22:71-76.

8. Freitas JE, Freitas AE. Thyroid and parathyroid imaging. Semin Nucl Med 1994; 24:234-245.

9. Takashima S, Fukuda H, Nomura N, Kishimoto H, Kim T, Kobayashi T. Thyroid nodules: reevaluation with ultrasound. J Clin Ultrasound 1995; 23:179-184.

10. Rago T, Vitti P, Chiovato L, et al. Role of conventional ultrasonography and color flow-Doppler sonography in predicting malignancy in "cold" thyroid nodules. Eur J Endocrinol 1998; 138:4146.

11. Papini E, Guglielmi R, Bianchini A, et al. Risk of malignancy in nonpalpable thyroid nodules: predictive value of ultrasound and color-Doppler features. J Clin Endocrinol Metab 2002; 87:1941-1946.

12. Gorman B, Charboneau JW, James EM, et al. Medullary thyroid carcinoma: role of highresolution US. Radiology 1987; 162:147-150.

13. Saller B, Moeller L, Görges R, Janssen OE, Mann K. Role of conventional ultrasound and color Doppler sonography in the diagnosis of medullary thyroid carcinoma. Exp Clin Endocrinol Diabetes. 2002; 110:403-407.

14. Nam-Goong IS, Kim HY, Gong G, et al. Ultrasonography-guided fine-needle aspiration of thyroid incidentaloma: correlation with pathological findings. Clin Endocrinol (Oxf) 2004; 60:21-28.

\section{AUTHORS:}

1. Mumtaz Ahmad Ansari

\section{PARTICULARS OF CONTRIBUTORS:}

1. Associate Professor, Department of General Surgery, Institute of Medical Sciences, Banaras Hindu University.

\section{NAME ADDRESS EMAIL ID OF THE CORRESPONDING AUTHOR: \\ Dr. Mumtaz Ahmad Ansari, Department of General Surgery, Institute of Medical Sciences, Banaras Hindu University. \\ E-mail: mumtazbhu@gmail.com}

Date of Submission: 06/02/2014. Date of Peer Review: 07/02/2014. Date of Acceptance: 12/02/2014. Date of Publishing: 18/02/2014. 